Article

\title{
The Activity of Isoquinoline Alkaloids and Extracts from Chelidonium majus against Pathogenic Bacteria and Candida sp.
}

\author{
Sylwia Zielińska ${ }^{1, * \mathbb{C}}$, Magdalena Wójciak-Kosior ${ }^{2}$, Magdalena Dziągwa-Becker ${ }^{3}$, \\ Michał Gleńsk ${ }^{4}$, Ireneusz Sowa ${ }^{2}$ (D) Karol Fijałkowski ${ }^{5}{ }^{\circledR}$, Danuta Rurańska-Smutnicka ${ }^{6}$, \\ Adam Matkowski ${ }^{1,7}$ (D) and Adam Junka ${ }^{6}(\mathbb{D}$ \\ 1 Department of Pharmaceutical Biology, Wroclaw Medical University, Borowska 211, 50-556 Wroclaw, Poland \\ Department of Analytical Chemistry, Medical University of Lublin, Chodźki 4a, 20-093 Lublin, Poland \\ 3 Departament of Weed Science and Tillage Systems, Institute of Soil Science and Plant Cultivation, \\ Orzechowa 61, 50-540 Wrocław, Poland \\ 4 Department of Pharmacognosy, Wroclaw Medical University, Borowska 211a, 50-556 Wroclaw, Poland \\ 5 West Pomeranian University of Technology in Szczecin, Faculty of Biotechnology and Animal Husbandry, \\ Department of Immunology, Microbiology and Physiological Chemistry, Piastów 45, 70-311 Szczecin, Poland \\ 6 Pharmaceutical Microbiology and Parasitology, Wroclaw Medical University, Borowska 211a, \\ 50-556 Wroclaw, Poland \\ 7 Laboratory of Experimental Cultivation, Botanical Garden of Medicinal Plants, Wroclaw Medical University, \\ Al. Jana Kochanowskiego 14, 50-556 Wroclaw, Poland \\ * Correspondence: sylwia.zielinska@umed.wroc.pl
}

Received: 13 June 2019; Accepted: 11 July 2019; Published: 12 July 2019

\begin{abstract}
Chelidonium majus (Papaveraceae) extracts exhibit antimicrobial activity due to the complex alkaloid composition. The aim of the research was to evaluate the antimicrobial potential of extracts from wild plants and in vitro cultures, as well as seven major individual alkaloids. Plant material derived from different natural habitats and in vitro cultures was used for the phytochemical analysis and antimicrobial tests. The composition of alkaloids was analyzed using chromatographic techniques (HPLC with DAD detection). The results have shown that roots contained higher number and amounts of alkaloids in comparison to aerial parts. All tested plant extracts manifested antimicrobial activity, related to different chemical structures of the alkaloids. Root extract used at 31.25-62.5 mg/L strongly reduced bacterial biomass. From the seven individually tested alkaloids, chelerythrine was the most effective against $P$. aeruginosa (MIC at $1.9 \mathrm{mg} / \mathrm{L}$ ), while sanguinarine against $S$. aureus (MIC at $1.9 \mathrm{mg} / \mathrm{L}$ ). Strong antifungal activity was observed against $C$. albicans when chelerythrine, chelidonine, and aerial parts extract were used. The experiments with plant extracts, individually tested alkaloids, and variable combinations of the latter allowed for a deeper insight into the potential mechanisms affecting the activity of this group of compounds.
\end{abstract}

Keywords: isoquinoline alkaloids; antimicrobial activity; Chelidonium majus

Key Contribution: Major isoquinoline alkaloids from Chelidonium majus are active against several pathogenic bacteria and yeast. Sanguinarine and chelerythrine are most efficient against Gram positive and Gram negative strains; respectively.

\section{Introduction}

Phytochemical characterization of the raw material enables one to recognize the production patterns of the plant compounds accumulated in response to the environmental factors. The composition and 
proportions of individual components are of great importance from the herbal drug usefulness point of view. Such studies should be conducted on a large number of samples due to the multitude of factors that may affect the phytochemical profile of plants. This can be done, inter alia, by comparing metabolite compositions in plants collected from natural habitats and in vitro cultures.

For our research, we have chosen a well-known medicinal plant Chelidonium majus L. (greater celandine). The species has a long tradition of being used mainly in folk medicine. It has been used in herbal medicine since Dioscorides and Pliny the Elder times, in the 1st century AD [1]. So far, anticancer, antimicrobial (antibacterial, antiviral, antifungal), antiprotozoal, anti-inflammatory, antispasmodic, spasmolytic, cholekinetic, muscle relaxant activities of C. majus extracts and several separated compounds have been reported [1]. The most abundant specialized metabolites produced in aerial and underground (roots and root collar, hereafter referred to as "roots") parts of the plant are isoquinoline alkaloids, mostly derivatives of benzophenantridine (chelidonine, chelerythrine, sanguinarine) protoberberine (berberine, coptisine, stylopine), and protopine (protopine, allocryptopine). The bioactivity of individual alkaloids has been linked, among others, to the presence of a methoxy substitutions, the iminium bond, a charge due to a quaternary nitrogen atom, a methyl group bonded to the quaternary nitrogen atom or lack of this substitution [2-8]. The published results do not always coincide or complement each other, or they are contradictory. Despite many multidirectional studies, the complex alkaloid composition of the species is still unexplored, and so is the bioactive potential of the plant [9-15].

In this study, we evaluated antimicrobial activity of seven alkaloids and C. majus extracts from plants derived from natural habitats and in vitro cultures. A comparison of the alkaloid profile of extracts obtained from aerial parts and roots of plants collected from different habitats was also performed using chromatographic techniques. Moreover, antimicrobial activity of seven major alkaloids was tested and the results were correlated with alkaloid content.

\section{Results}

\subsection{Comparison of Extraction Effectiveness}

HPLC analysis showed the presence of seven major alkaloids of the three main classes (phenanthridine: chelidonine, chelerythrine, sanguinarine; protoberberine: berberine, coptisine; protopine: allocryptopine, protopine). Chemical structures of the compounds are presented in Figure 1. The content of these alkaloids in extracts obtained with the use of various solvents expressed as $\mu \mathrm{g}$ on $\mathrm{g}$ of dried plant material is shown in Figures 2-4.

The aerial and underground parts differed significantly in the content of alkaloids (Figures 2 and 3). The blooming herb after separating the fruits, was rich in chelidonine, while in the separated fruits coptisine was the most abundant alkaloid (Figure 5). Roots were generally a much alkaloid richer raw material. The content of all alkaloids was much higher in roots than in aerial parts. There was a particularly high content of sanguinarine, chelidonine, chelerythrine, and allocryptopine in the samples collected from all five habitats. The most abundant compound in roots was sanguinarine (1986.43 $\mu \mathrm{g} / \mathrm{g}$ d.w.), and its highest content was recorded in the plants from habitat E (Szukalice, Lipowa). In aerial parts, coptisine was a predominant compound (857.29 and $4979.12 \mu \mathrm{g} / \mathrm{g} \mathrm{d.w}$ ). The highest content of coptisine was found in plants from habitat A (Wrocław, Kochanowskiego).

The analysis across multiple test attempts using different concentrations of extraction solvent showed no tied ranks. The yield of all seven alkaloids was highest at the methanol concentration of $80 \%$, compared to $70 \%$ and $90 \%$. There were large differences between 70 and $80 \%$, and much smaller between 80 and $90 \%$.

Methanol extraction of $80 \%$ was found to be the most effective in terms of alkaloids recovery (Figure 4).

The representative chromatograms are presented in Figure 5. 
phenanthridine

derivatives

$(+)$-chelidonine

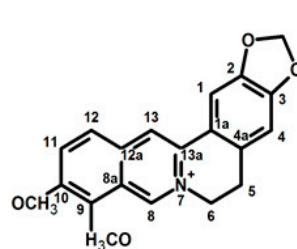

berberine

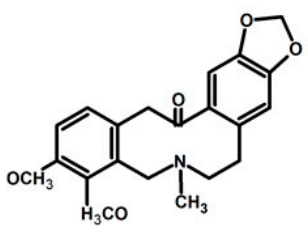

allocryptopine

protoberberine derivatives

protopine derivatives
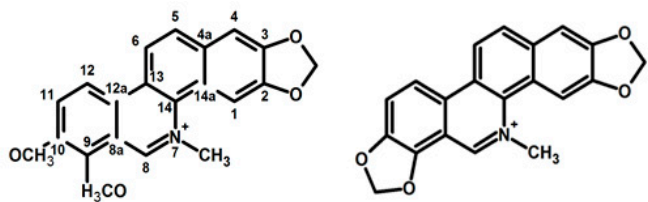

chelerythrine sanguinarine (y-chelerythrine)

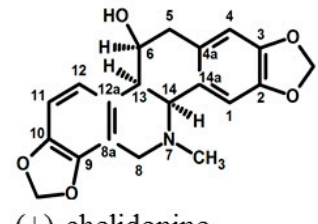

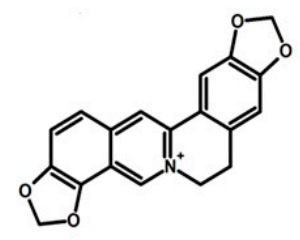

coptisine<smiles>CN(C)CCc1c(CN(C)CCc2cc3c(cc2C(=O)CO)OCO3)ccc2c1OCO2</smiles>

protopine

Figure 1. Structures of isoquinoline alkaloids present in C. majus.

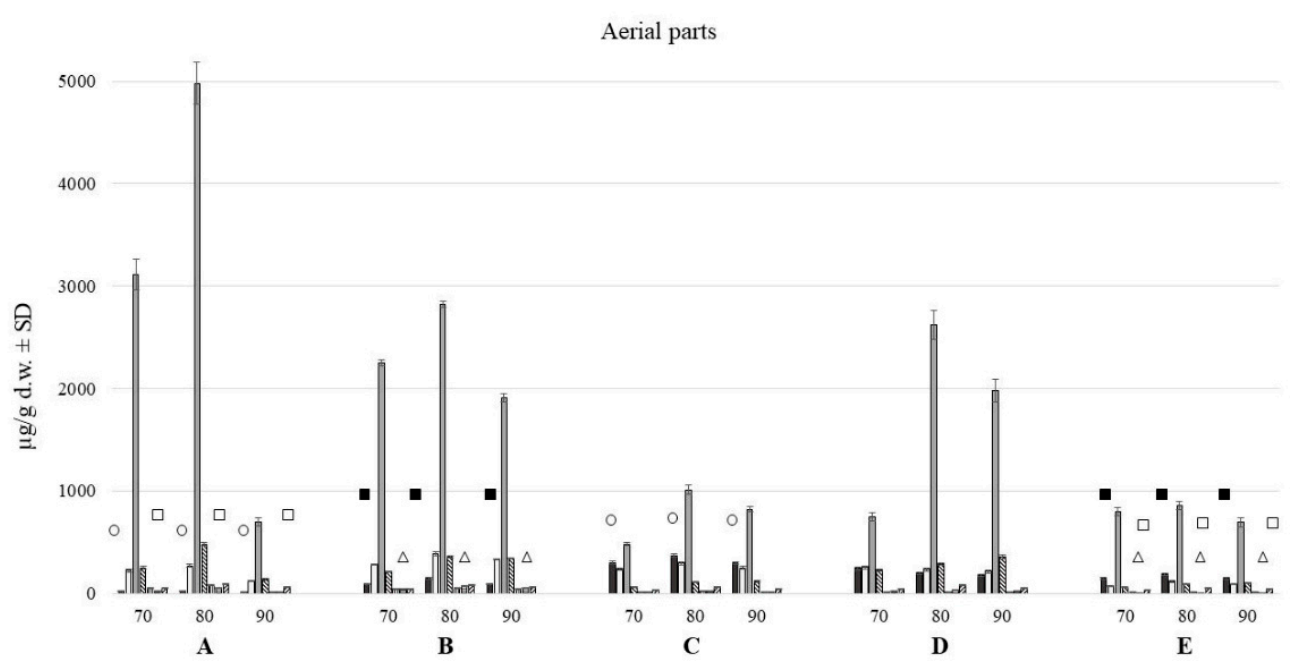

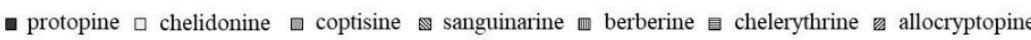

Figure 2. Isoquinoline alkaloids content in aerial parts with fruits of $C$. majus collected from different habitat (70, 80, 90\% of methanol acidified with $50 \mathrm{mM} \mathrm{HCl}$; A-E-different habitats). Statistically significant differences in the content of each compound between plants harvested from five different habitats are presented as marks of the same shape and color; protopine—white circle, chelidonine—black squares, chelerythrine - white triangles, allocryptopine-white squares, no marks-no statistically significant differences. 


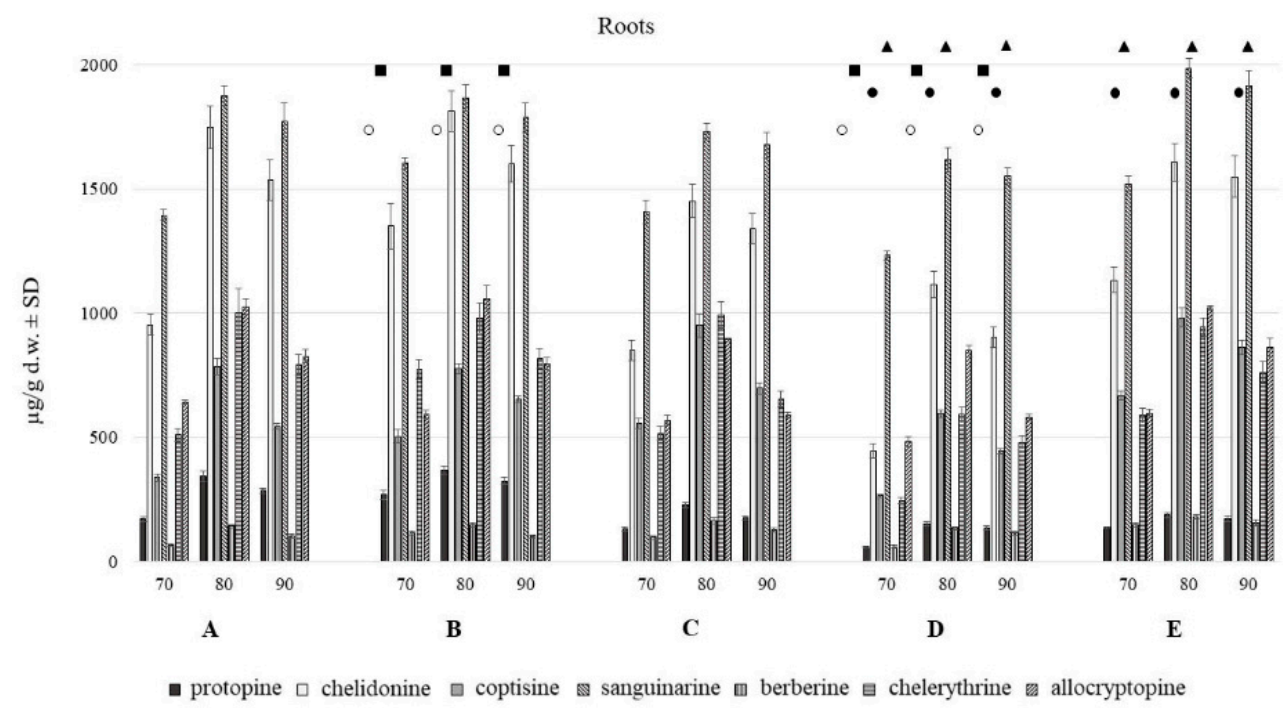

Figure 3. Isoquinoline alkaloids content in roots of C. majus collected from different habitat (70, $80,90 \%$ of methanol acidified with $50 \mathrm{mM} \mathrm{HCl}$; A-E-different habitats). Statistically significant differences in the content of each compound between plants harvested from five different habitats are presented as marks of the same shape and color; protopine-white circle, chelidonine-black squares, coptisine-black circles, sanguinarine-black triangles, chelerythrine - white triangles, no marks-no statistically significant differences.

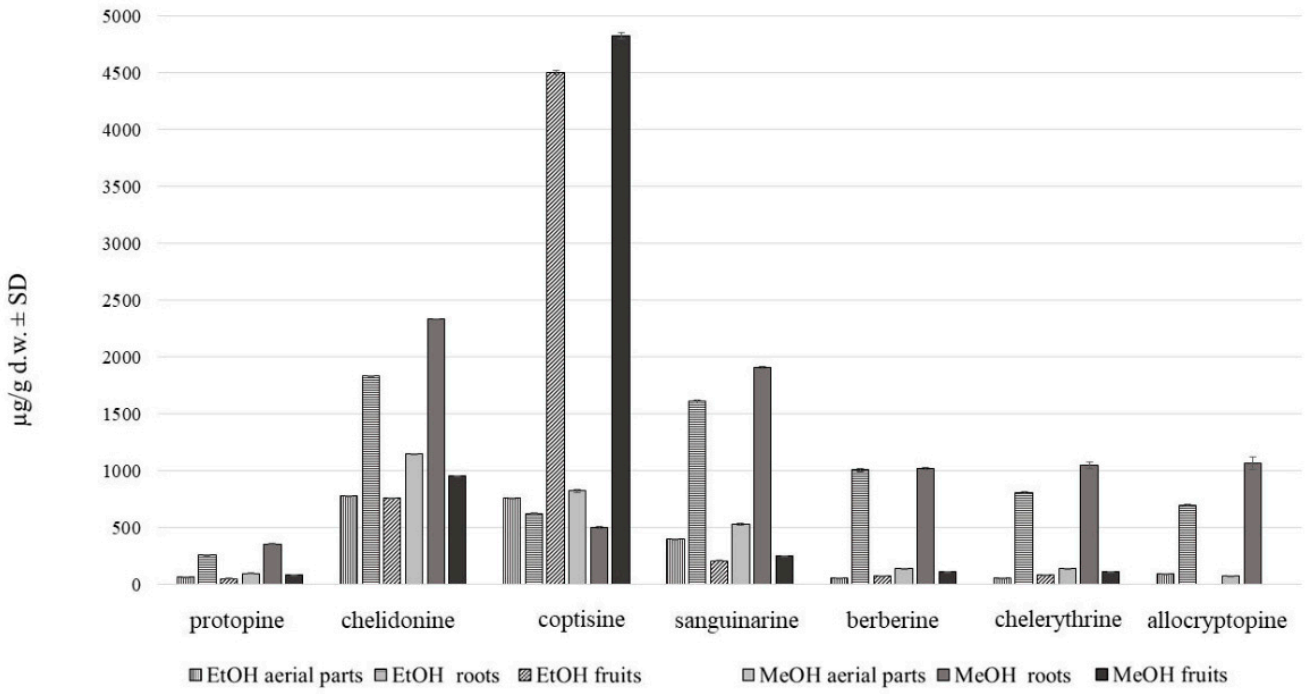

Figure 4. Alkaloid content in C. majus methanol and ethanol extracts of aerial parts and roots ( $\mu \mathrm{g} / \mathrm{g}$ d.w. $\pm \mathrm{SD})$ collected from place A. 


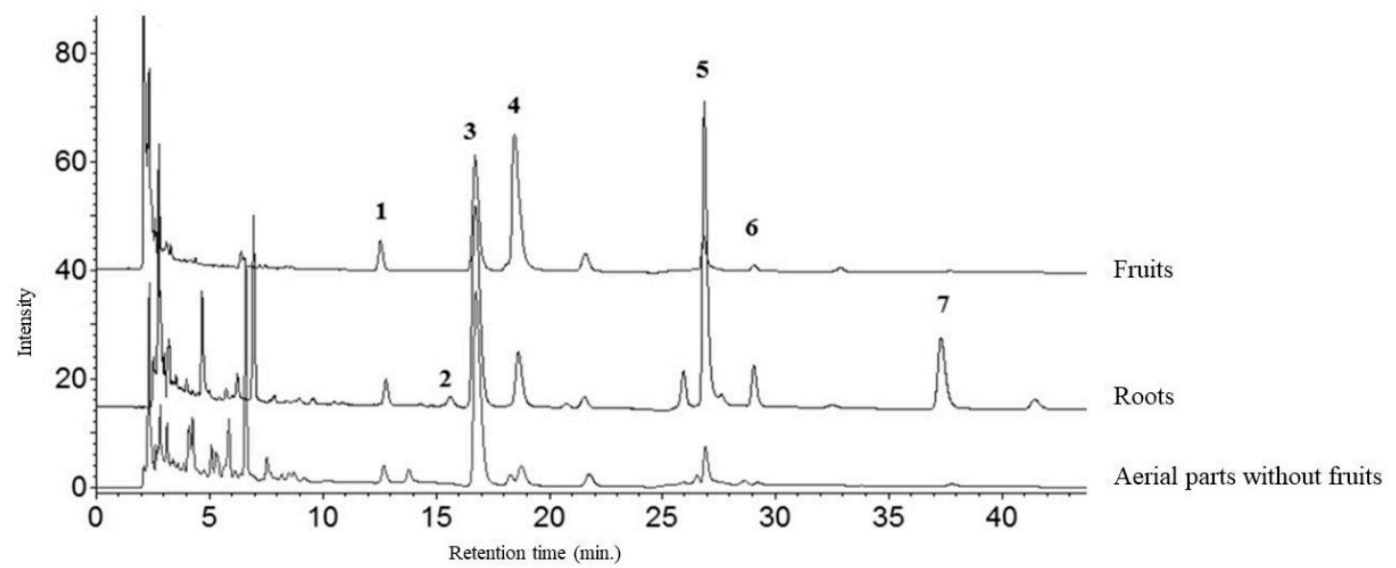

1-protopine, 2-allocryptopine, 3- chelidonine, 4-coptisine, 5- sanguinarine, 6- berberine, 7- chelerythrine

Figure 5. HPLC-DAD chromatogram of alkaloids (acquired at $290 \mathrm{~nm}$ ) in extracts of C. majus fruits, aerial parts without fruits, and roots.

Differences in the alkaloids content were also found among five different habitats (A-E). The content of individual alkaloids depends on the locality of the plant harvest, and it is different for individually analyzed alkaloids from roots and aerial parts evaluated separately.

\subsection{MIC Evaluation}

Extracts of aerial parts and roots of $C$. majus derived from natural habitats and in vitro cultures were used for the antimicrobial assays.

None of the applied extracts was active against K. pneumoniae, P. aeruginosa and E. coli strains, which are Gram-negative bacteria.

In the case of Gram-positive pathogen S. aureus, MIC of roots $\mathrm{MeOH}$ extract was $62.5 \mathrm{mg} / \mathrm{L}$ (Table 1 ). Also, a strong reduction of bacterial biomass (49\%) in comparison to untreated bacteria was observed when $31.25 \mathrm{mg} / \mathrm{L}$ of this extract was used.

Individually tested alkaloids displayed MIC against S. aureus and P. aeruginosa in the range between 1.9 and $125 \mathrm{mg} / \mathrm{L}$, depending on the compound, and between $31.25-62.5 \mathrm{mg} / \mathrm{L}$ against C. albicans, depending on the compound (Figure 6). Chelerythrine was the most effective, of all tested compounds against $P$. aeruginosa (MIC at $1.9 \mathrm{mg} / \mathrm{L}$ ), whereas sanguinarine was the most effective against $S$. aureus (MIC at $1.9 \mathrm{mg} / \mathrm{L}$ ).

Berberine and allocryptopine were the least effective-reduction of $100 \%$ of S. aureus bacterial biomass was observed when $125 \mathrm{mg} / \mathrm{L}$ of compounds were tested.

Strong fungal biomass reduction was observed for C. albicans when aerial parts extract was used, however no MIC was observed in analyzed range of concentrations.

Only chelerythrine and chelidonine were active enough to allow calculation of MIC (31.25 and $62.5 \mathrm{mg} / \mathrm{L}$, respectively) against $C$. albicans.

The MIC of combined sanguinarine-chelerythrine-chelidonine against $S$. aureus and P. aeruginosa was 3.12 and $6.25 \mathrm{mg} / \mathrm{L}$, respectively, of mixture was used (Figure 7). Sanguinearine-chelerythrine and sanguinarine-chelerythrine-berberine mixtures were much more effective against $S$. sureus than against P. aeruginosa and C. albicans (Figure 7). 
Table 1. Antimicrobial activity of methanolic extracts from intact plants and in vitro plant material. Asterisk indicates concentration which was able to inhibit $100 \%$ of microbial inoculum (i.e., Minimum Inhibitory Concentration-MIC (mg/L).); no asterisk next to value represents situation when at least $70 \%$ of microbial cell was reached; "minus" sign stands for very weak ability of extract to reduce colony-forming unit (cfu) number.

\begin{tabular}{ccc}
\hline Solvent/Plant Material & Candida albicans & Staphylococcus aureus \\
\hline MeOH aerial & - & - \\
MeOH roots & - & $62.5^{*}$ \\
\hline Culture medium/plant material & Candida albicans & Staphylococcus aureus \\
\hline MS roots & 125 & $500^{*}$ \\
MS shoots & $500^{*}$ & $500^{*}$ \\
MS+N roots & 3.9 & $500^{*}$ \\
MS+N shoots & 3.9 & $500^{*}$ \\
$\frac{1}{2}$ MS roots & - & - \\
$\frac{1}{2}$ MS shoots & - & - \\
$1.5 \%$ suc. + N roots & - & - \\
$1.5 \%$ suc. + N shoots & 500 & 250 \\
$1.5 \%$ suc. roots & 250 & 125 \\
$1.5 \%$ suc. shoots & 500 & $500^{*}$ \\
B5 roots & - & $250^{*}$ \\
B5 shoots & - & $500^{*}$ \\
B5 + N roots & - & - \\
B5 + N shoots & - & $250 *$ \\
\hline
\end{tabular}

MS-standard culture medium [16]; $\frac{1}{2}$ MS-medium with reduced macro-, and microelements concentration; B5-standard culture medium [17]; $+\mathrm{N}-$ supplementation with double amount of $\mathrm{NH}_{4}^{+}$ions and simultaneous depletion of an equivalent amount of nitrate ions; $1.5 \%$ suc-MS medium supplemented with $1.5 \%$ of sucrose.

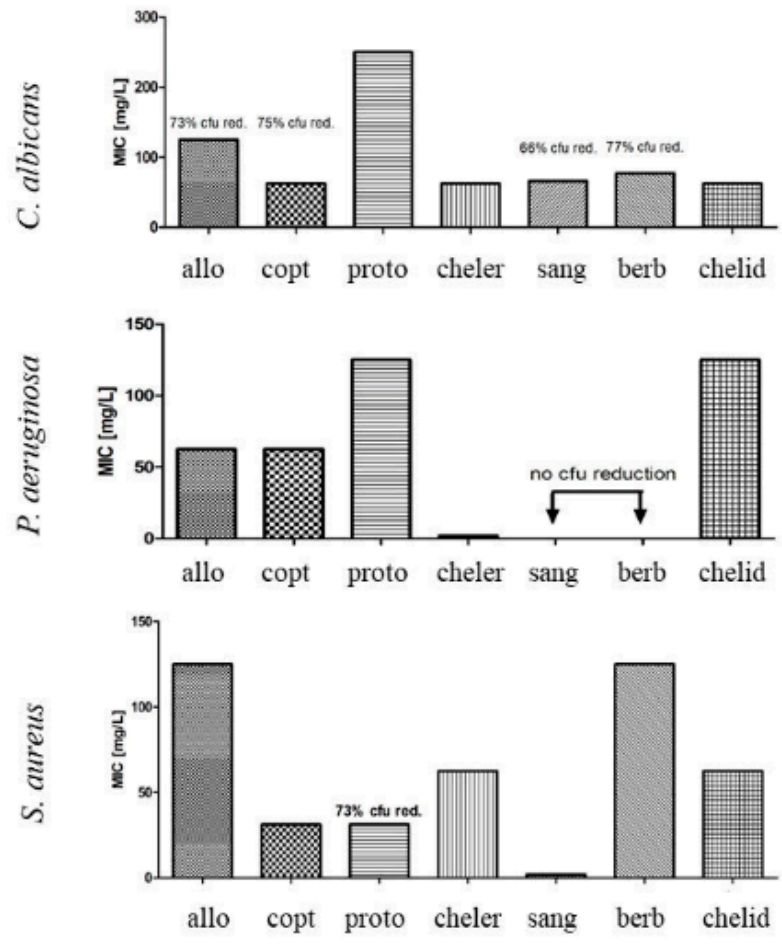

Figure 6. A comparison of Minimum Inhibitory Concentration (MIC) of the following alkaloids: allo= allocryptopine, copt $=$ coptisine, proto $=$ protoberberine, cheler $=$ chelerythrine, sang = sanguinarine, berb = berberine, chelid $=$ chelidonine 

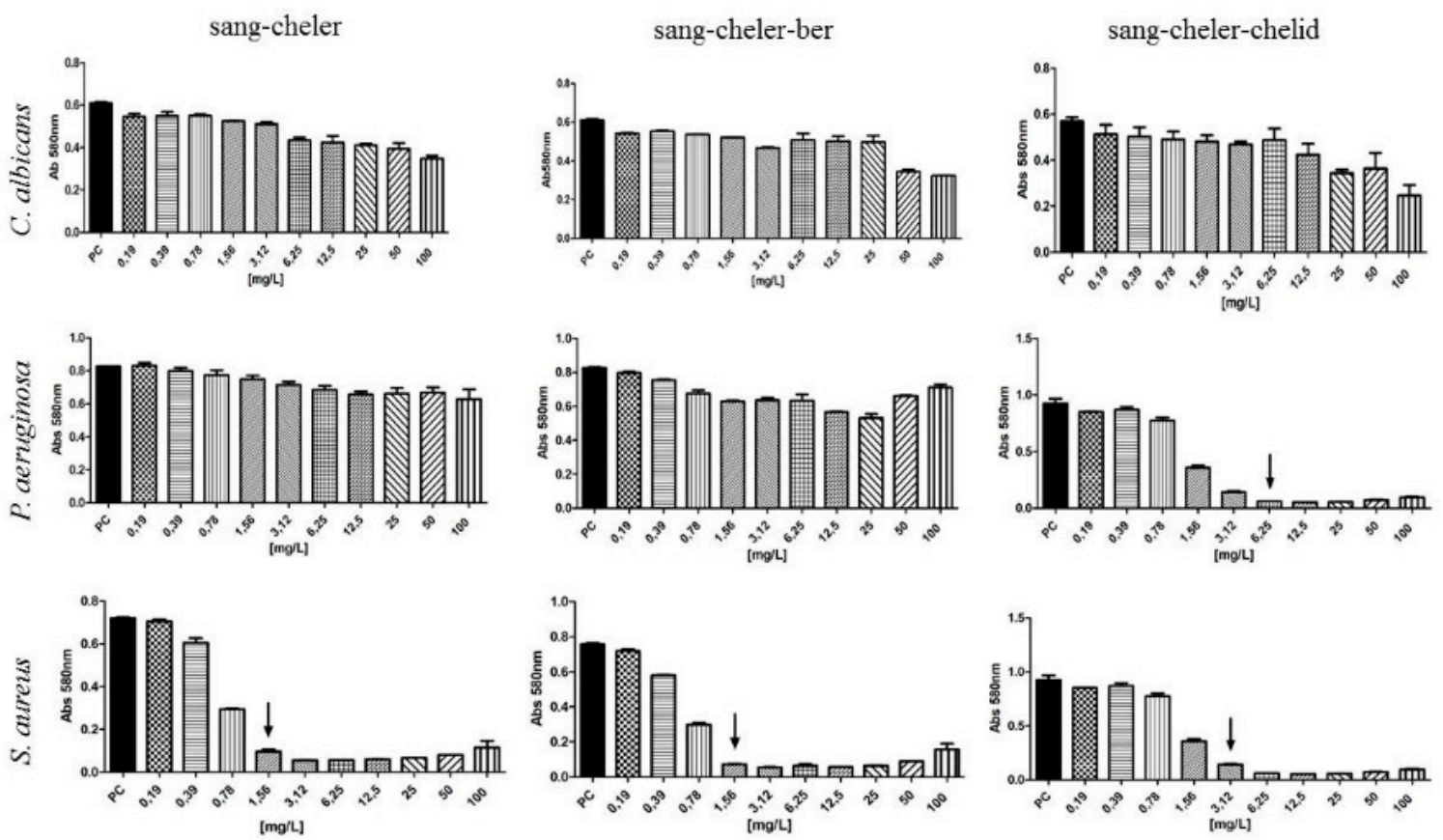

Figure 7. Antimicrobial activity of alkaloid mixtures. Arrows indicate MIC; sang = sanguinarine, cheler $=$ chelerythrine, berb $=$ berberine , chelid $=$ chelidonine .

\subsection{Cytotoxicity}

Berberine, protopine and allocryptopine displayed no cytotoxic effect against L929 fibroblast cell lines in concentration of $15.6 \mathrm{mg} / \mathrm{L}$; lack of cytotoxicity was observed for coptisine when $7.8 \mathrm{mg} / \mathrm{L}$ of this compound was introduced to L929 cell line; chelidonine and chelerythrinine displayed no cytotoxic effect in concentration of $3.9 \mathrm{mg} / \mathrm{L}$. Cytotoxic properties were exhibited by sanguinarine which displayed adverse effects towards $\mathrm{L} 929$ cell line at concentrations of $500 \mu \mathrm{g} / \mathrm{L}$ or higher.

\section{Discussion}

The phytochemical profile that determines the biological activity of the raw material is difficult to characterize due to a large number of compounds produced in the plant and the multitude of factors determining their formation. For this reason, we compared the results of the bioactivity assays performed using plants harvested from different natural habitats, the in vitro cultures, as well as seven individual alkaloids and their mixtures.

So far, both herb and C. majus root and root collars as underground parts were considered to be rich in alkaloids, and hence they were used, mainly in folk medicine [1]. Our research has shown that roots of the species form a much richer source of these compounds in terms of their quality and quantity. It has been noted for both the in vitro and in vivo plant material. In turn, a kind of variation within the resulting composition of each plant parts was observed among samples collected from different habitats (Figures 2 and 3) as well as from different in vitro culture treatment [9].

MIC of methanol extracts of aerial parts and roots, as well as in vitro cultures of shoots and roots was observed against Gram-positive bacteria when $31.25-62.5 \mathrm{mg} / \mathrm{L}$, and 125-250 mg/L were used, respectively. Sanguinarine was found to be the most abundant constituent in plant extracts $(2-4 \mathrm{mg} / \mathrm{g}$ d.w. in intact plants and in vitro cultures. The amounts of other alkaloids were much lower in the extracts except coptisine (almost $5 \mathrm{mg} / \mathrm{g}$ d.w.). In individual tests, all seven alkaloids exhibited, to various extent, activity against Gram-positive strain. Sanguinarine was the most potent with MIC at $1.9 \mathrm{mg} / \mathrm{L}$, followed by coptisine, protopine, chelerythrine, chelidonine, berberine, and allocryptopine. This kind of activity was previously reported in the earlier research on celandine alkaloids [18-21]. These experiments showed that chelerythrine and sanguinarine were more effective against these 
bacteria than chelidonine and berberine. In our study, sanguinarine exhibited several to several dozen times stronger activity than coptisine (MIC $31.25 \mathrm{mg} / \mathrm{L}$ ), chelerythrine and chelidonine (MIC 62.5 mg/L), or allocryptopine and berberine (MIC $125 \mathrm{mg} / \mathrm{L}$ ). Sanguinarine activity was also stronger than roots methanolic extract rich in the compound (1617.91-1986.43 $\mu \mathrm{g} / \mathrm{g}$ d.w.). The extract was effective when the concentration of $62.5 \mathrm{mg} / \mathrm{L}$ was used. On the other hand, sanguinarine alone was slightly less active (MIC $1.9 \mathrm{mg} / \mathrm{L}$ ) against Gram-positive bacteria than mixtures of sanguinarine with chelerythrine or sanguinarine with chelerythrine and berberine (MIC $1.56 \mathrm{mg} / \mathrm{L}$ ).

In Kokoška et al. (2002) [22] experiments with multidrug-resistant bacteria existing in surgical wounds and infections of critically ill patients, C. majus root ethanol extract was also found to be effective against Gram-positive bacteria (S. aureus, Bacillus cereus) (MIC 15.63 and $62.5 \mathrm{mg}$ of dry plant material $/ \mathrm{ml}$, respectively), but was inactive against Gram-negative (P. aeruginosa). Also, the concentration of $62.5 \mathrm{mg}$ of dry plant material $/ \mathrm{ml}$ effectively inhibited C. candida in these experiments. The aerial parts of C. majus used in the study of Kokoška et al. (2002) [22] were inactive against any of the test microbes.

Other studies in which methanolic extracts of $C$. majus were used are also consistent with the results from our experiments. Methanol extracts from leaves and petioles of $C$. majus plants grown in nature, as well as in vitro cultures [23] were potent against Gram-positive, rather than Gram-negative strains. In these studies, methanolic extracts were examined against Bacillus subtilis, Micrococcus luteus, Sarcinia lutea, and S. aureus, E. coli, Proteus mirabilis, Salmonella enteritidis, and clinically isolated C. albicans. Both, in vivo and in vitro plant material extracts exhibited similar bioactivity. Only some extracts were comparable against E. coli, S. enteritidis, and C. albicans to reference antibacterial and antifungal drugs (streptomycin, bifonazole, respectively), whereas the rest of them showed low or no activity [23].

None of the extracts, as well as sanguinarine and berberine alone were active against a Gram-negative bacteria ( $P$. aeruginosa). However, other individually tested alkaloids displayed various degrees of activity against $P$. aeruginosa with MIC ranging between 1.9 and $125 \mathrm{mg} / \mathrm{L}$ (Figure 6). Chelerythrine was found to be the most potent $(1.9 \mathrm{mg} / \mathrm{L})$, followed by allocryptopine, coptisine $(62.5 \mathrm{mg} / \mathrm{L})$, and protopine, chelidonine $(125 \mathrm{mg} / \mathrm{L})$. In other studies, chelerythrine was also able to eradicate Gram-negative bacteria (P. aeruginosa, E. coli, Klebsiella pneumoniae, Salmonella gallinarum, S. typhi, S. paratyphi, Proteus vulgaris, Shigella flexneri, Vibrio cholerae) [18-21,24,25]. Nevertheless, sanguinarine and berberine were also listed as effective against Gram negative strains in the mentioned studies, which was not corroborated by our results.

The combined sanguinarine-chelerythrine-chelidonine were able to inhibit $100 \%$ of microbial inoculum when $6.25 \mathrm{mg} / \mathrm{L}$ of mixture was used. These results indicated that chelidonine may have an additional effect when combined with other alkaloids. It may be due to the chemical structure of chelidonine, which is different than sanguinarine and chelerythrine. Chelidonine is a benzoisoquinoline alkaloid with a tertiary nitrogen in the molecule, unlike sanguinarine and chelerythrine, which both contain a quaternary nitrogen atom (Figure 1) whose charge can depend on the $\mathrm{pH}$ also in the microenvironment of the bacterial cells. Various types of alkaloid bioactivity at the cellular level due to the differences in their chemical structure were well documented in the study of Barreto et al. (2003) [6]. In experiments with several groups of isoquinoline alkaloids on oxygen uptake in mouse liver mitochondria, these three alkaloids have shown a different scheme of action due to their chemical structure [6]. Generally, phenanthrene skeleton had a very low effect on oxygen uptake, while other building elements of individual alkaloids seemed to be important. Chelerythrine and sanguinarine, strongly inhibited succinate-dependent respiration and, to a lesser extent, malate-glutamate respiration, whereas chelidonine had no apparent effect. Allocryptopine, an uncharged molecule with a $\mathrm{C}=\mathrm{O}$ group, similarly to chelidonine, was not effective. In Barreto et al. (2003) [6] study, the manner of compounds action was linked to the degree of substitution of a nitrogen atom in a molecule. In turn, berberine and coptisine, both with an unsubstituted quaternary nitrogen atom, have shown a marked inhibitory effect on malate-glutamate respiration and a smaller, although significant, effect on succinate respiration. The presence of a methyl group seems to be of less importance for the direction of biological activity. 
Chelerythrine, sanguinarine, and chelidonine contain methyl group but they present different activity pattern against microorganisms [26].

In case of antifungal assays, among seven individually tested alkaloids, only chelerythrine and chelidonine, as well as extracts from in vitro-derived shoots, were able to inhibit $100 \%$ of $C$ albicans colony forming units $(31.25,62.5$, and $500 \mathrm{mg} / \mathrm{L}$, respectively). Five other alkaloids, their mixtures, as well as in vivo and in vitro plant extracts showed no MIC in the analyzed range of concentrations. However, a strong fungal biomass reduction was observed (Figure 6, Table 1). The observation of other researchers has shown similar results, only with chelerythrine, sanguinarine, and their derivatives being up to several times more effective against pathogenic fungi than chelidonine [26-28]. Extracts from roots and shoots cultured in vitro on two different standard media, namely MS and B5, exhibited varied effect against $C$. albicans. It was probably related to the differences in the composition of micro and macro elements, sucrose and vitamins between the two culture media.

Microbes, during their the long evolutionary journey developed a plethora of systems aiming to evade or neutralize antimicrobial agents. It concerns not only human or animal pathogens but also environmental strains which co-exist in complex, multi-species habitat in water or soil having contact with plants [29-31].

In turn, it was proven, that bacterial pathogens in nosocomial environment are able to actively pump biocides out from their cytoplasm using "efflux pump" systems. It is also known that these mechanisms may be of un-specific nature, i.e., efflux pump activation as result of presence of specific biocide may activate bacterial organism to pump out wide spectrum of other biocides. An increased resistance to chlorhexidine antiseptic and cross-resistance to colistin antibiotic following exposure to chlorhexidine in Klebsiella pneumoniae is one of the most studied examples of such a phenomenon [32]. Such a mechanism may explain results obtained by us and other researchers showing various levels of antimicrobial activity of alkaloids provided alone or in mixture.

\section{Conclusions}

The complex composition of $C$. majus alkaloids contained in plant extracts can manifest a wide spectrum of antimicrobial activity, arising from structural diversity of the compounds. Alkaloids from all parts of $C$. majus and from in vitro biomass may find an application in eradication of both Gram-positive and Gram-negative cocci. They are also promising against Candida pathogens. Further detailed studies are necessary to fully understand the mechanisms of activity associated with the chemical structures of isoquinoline alkaloids. The rational design of the composition of alkaloids should be envisaged to combat various microbes depending on the activity of individual components and for this to happen, the natural proportions of the alkaloids in plant matricies can be manipulated both by means of plant treatment and post-harvest processing of the crude biomass and extracts obtained thereof. In further studies on C. majus, the factors at work that orchestrate the alkaloid profile and their strain-specific activity should be elucidated.

\section{Materials and Methods}

\subsection{Plant Material}

\subsubsection{Wild Growing Plants}

The studied plants were collected from five different locations in Poland: A: (Wrocław, Kochanowskiego Street $51^{\circ} 07^{\prime} 01.6^{\prime \prime} \mathrm{N} 17^{\circ} 04^{\prime} 26.7^{\prime \prime E 51.117121, ~ 17.074088-28.05 .2017), ~ B: ~(W r o c ł a w, ~}$ Kosciuszki Street $\left.51^{\circ} 06^{\prime} 08.0^{\prime \prime} \mathrm{N} \quad 17^{\circ} 02^{\prime} 08.9^{\prime \prime} \mathrm{E} 51.102220,17.035811-30.05 .2017\right), \quad \mathrm{C}$ : (Turawa $50^{\circ} 44^{\prime} 45.9^{\prime \prime} \mathrm{N} 18^{\circ} 02^{\prime} 29.1^{\prime \prime}$ E50.746071， 18.041428-11.06.2017), D: (Wrocław, Borowska Street $\left.51^{\circ} 04^{\prime} 42.0^{\prime \prime} \mathrm{N} 17^{\circ} 01^{\prime} 51.9^{\prime \prime} \mathrm{E} 51.078325,17.031080-25.05 .2017\right)$, E: (Szukalice, Lipowa Street $51^{\circ} 00^{\prime} 07.4^{\prime \prime} \mathrm{N}$ $\left.17^{\circ} 00^{\prime} 40.4^{\prime \prime} \mathrm{E} 51.002062,17.011213-22.05 .2017\right)$. The habitats of plants were overshadowed roadsides, 
as well as forest edges and shrubbery. The maximum distance between the localities was up to $150 \mathrm{~km}$ and minimum was $3 \mathrm{~km}$.

\subsubsection{In Vitro Plant Material}

Plant material from in vitro cultures was used for the analysis and bioactivity assays. The in vitro cultures establishment, as well as extraction procedures for the phytochemical analysis, were presented previously [9].

\subsection{Phytochemistry}

\subsubsection{Reagents and Standards}

Alkaloid standards such as protopine (purity $\geq 95$ ), berberine (purity $\geq 95 \%$ ), chelidonine (purity $\geq 95 \%$ ), chelerythrine (purity $\geq 90 \%$ ), and sanguinarine (purity $\geq 90 \%$ ) were purchased from Extrasynthese (France) and allocryptopine, (purity $\geq 95$ ), coptisine (purity $\geq 98 \%$ ) from Sigma (St. Louis, MO, USA). Ammonium acetate, acetic acid, HPLC grade methanol (MeOH), and acetonitrile (ACN) were from Merck (Darmstadt, Germany). Water was deionized and purified by ULTRAPURE Millipore Direct-QVR 3UV-R (Merck, Darmstadt, Germany).

Alkaloid mixtures used for bioactivity assays were obtained from the following sources:

sanguinarine (Sang), chelerythrine (Cheler) were isolated as a mixture from Coptis chinensis rhizoma (19g/100g yield). Three mixures were used: Sang-Cheler (0.2:1 w/w); Sang-Cheler-Chelid $(0.2: 1: 1, w / w)$; Sang-Cheler-Berb $(0.2: 1: 1, w / w)$.

\subsubsection{Sample Preparation}

Dried raw material was divided into aerial parts (stems with leaves, flowers and fruits) and underground (roots and root collars) parts and powdered with mortar and pestle. The extraction of intact plants was performed in round-bottom flasks with a solvent to solid ratio of 1:20 (v:w) in ultrasonic bath $(3 \times 15 \mathrm{~min})$. Samples were extracted with methanol or ethanol and $50 \mathrm{mM}$ hydrochloric acid according to the procedure by Kulp et al. [33]. Additionally, extraction was conducted with acidified $(50 \mathrm{mM} \mathrm{HCl})$ aqueous methanol in three different proportions (90:10, 80:20 and 70:30 v/v). The extracts were combined, evaporated and dissolved in $20 \mathrm{ml}$ of methanol.

\subsubsection{HPLC Analysis}

Chromatography was carried out using a VWR Hitachi Chromaster 600 chromatograph (Merck, Darmstadt, Germany) with a spectrophotometric detector (DAD) and EZChrom Elite software (Merck). The samples were analyzed on an XB-C18 reversed phase core-shell column (Kinetex, Phenomenex, Aschaffenburg, Germany) ( $25 \mathrm{~cm} \times 4.6 \mathrm{~mm}$ i.d., $5 \mu \mathrm{m}$ particle size), kept at $25^{\circ} \mathrm{C}$. Mobile phase consisted of acetonitrile (A) and $10 \mathrm{mM}$ water solution of ammonium acetate adjusted to $\mathrm{pH} 4$ with acetic acid (B). Gradient elution program was as follows: from 0 to $20 \mathrm{~min}$ : 20\% A; from 20.5 to $27 \mathrm{~min} 25 \% \mathrm{~A}$ and from $27.5-60 \mathrm{~min}$. 30\% A at the flow rate of $1 \mathrm{~mL} / \mathrm{min}$. Chromatograms were recorded in the range of wavelength from 220 to $400 \mathrm{~nm}$. The identity of compounds in plant extracts was confirmed by comparison of retention times and spectra with corresponding standards. Peak homogeneity was established comparing the spectrum recorded at the three peak sections upslope, apex, and downslope with the reference spectrum. Additionally, the chromatographic fractions eluted at the retention time characteristic for the investigated alkaloids were collected using a Foxy R1 fraction collector (Teledyne Isco, Lincoln, NE, USA), and their identity was confirmed by direct injection mass spectrometry (micrOTOF-Q II, Bruker Daltonics, Bremen, Germany) using Compass DataAnalysis software version 4.1. The operating conditions were as follows: positive ionization mode, ion spray voltage: $4500 \mathrm{~V}$; fragmentator voltage: $-500 \mathrm{~V}$, corona discharge: $4000 \mathrm{nA}$, flow rate of nitrogen: $3.5 \mathrm{~L} / \mathrm{min}$, temperature of nitrogen: $200{ }^{\circ} \mathrm{C}$ and evaporator temperature: $350{ }^{\circ} \mathrm{C}$. The generated ions were analyzed in the range of $50-500 \mathrm{~m} / \mathrm{z}$. 
Quantitative analyses were performed at following wavelengths: $290 \mathrm{~nm}$ for protopine, allocryptopine and chelidonine, $359 \mathrm{~nm}$ for coptisine, $329 \mathrm{~nm}$ for sanguinarine, $346 \mathrm{~nm}$ for berberine, $318 \mathrm{~nm}$ for chelerythrine. Validation of the method was performed in our previous study [10].

\subsection{Statistical Analysis}

To explore differences in treatments (the content of protopine, allocryptopine, chelidonine, coptisine, chelerythrine, sanguinarine, and berberine) across multiple test attempts (different concentrations of extraction solvent, different habitats of intact plants) the Friedman ANOVA analysis followed by the Dunn test and Bonferroni correction was performed. The statistical significance of differences between treatments was considered significant at $p<0.05$. All statistical processing was performed using Microsoft Excel (Office 365, Microsoft, Redmont, WA, USA).

\subsection{Experimental Design for Bioactivity Assays}

To conduct the bioactive potential of $C$. majus extracts bioactivity assays against Gram-positive (Staphylococcus aureus), Gram-negative (Pseudomonas aeruginosa, Klebsiella pneumonia, Escherichia coli), and pathogenic yeast (Candida albicans).

\subsubsection{Strains}

The following microbial strains from ATCC collection were used for experimental purposes: Staphylococcus aureus 6538; Pseudomonas aeruginosa 14452; Klebsiella pneumoniae 700603; Escherichia coli 25922. Clinical fungal strain: Candida albicans 10231.

\subsubsection{MIC Evaluation}

Standard microdilution technique according to EUCAST guidelines was used to assess antimicrobial potential of the methanol extracts (from underground and aerial plant parts). Survival of cells subjected to extract's activity was assessed by the TTC assay (based on ability of colorless triphenyl tetrazolium chloride (TTC) compound to change into red formazan in the presence of living microbes; qualitative technique) and using spectrophotometry $(\lambda=600$; semi-quantitative technique).

Author Contributions: Conceptualization, S.Z. and A.J.; Methodology, S.Z., A.J., M.W.-K., I.S., K.F., and M.G.; Software, M.W.-K. and M.D.-B.; Validation, M.W.-K. and M.D.-B.; Formal Analysis, S.Z., M.W.-K., D.R.-S., A.J.; Investigation, S.Z. and A.J.; Resources, S.Z., A.M., A.J.; Data Curation, S.Z.; Writing-Original Draft Preparation, S.Z.; Writing-Review \& Editing, S.Z., M.W.-K., A.M., A.J.; Visualization, S.Z.; Supervision, A.J. and A.M.; Project Administration, A.J., A.M.; Funding Acquisition, A.J., A.M.

Funding: This research was funded by National Research Center grant number 2018/02/X/NZ4/01169 NCN MINIATURA-2" and the Wroclaw Medical University project SUB.D033.19.009.

Acknowledgments: This study was supported by National Research Center grant no. 2018/02/X/NZ4/01169 NCN MINIATURA-2 and the Wroclaw Medical University project SUB.D033.19.009. The authors thank Andrzej Dryś from the Department of Physical Chemistry, Wroclaw Medical University for his valued assistance in statistical analysis.

Conflicts of Interest: The authors declare no conflicts of interest.

\section{References}

1. Zielinska, S.; Jezierska-Domaradzka, A.; Wójciak-Kosior, M.; Sowa, I.; Junka, A.; Matkowski, A.M. Greater Celandine's ups and downs-21 centuries of medicinal uses of Chelidonium majus from the viewpoint of today's pharmacology. Front. Pharmacol. 2018, 9, 1-29. [CrossRef]

2. Miao, F.; Yanga, X.-J.; Zhou, L.; Hu, H.-J.; Zheng, F.; Ding, X.-D.; Sun, D.-M.; Zhou, C.-D.; Sun, W. Structural modification of sanguinarine and chelerythrine and their antibacterial activity. Nat. Prod. Res. 2011, 25, 863-875. [CrossRef]

3. Hossain, M.; Khan, A.Y.; Kumar, G.S. Interaction of the anticancer plant alkaloid sanguinarine with bovine serum albumin. PLOS ONE 2011, 6, e18333. [CrossRef] 
4. Giri, P.; Kumar, G.S. Specific binding and self-structure induction to poly(A) by the cytotoxic plant alkaloid sanguinarine. Biochim. Biophys. Acta 2007, 1770, 1419-1426. [CrossRef]

5. Bai, L.-P.; Zhao, Z.-Z.; Cai, Z.; Jiang, Z.-H. DNA-binding affinities and sequence selectivity of quaternary benzophenanthridine alkaloids sanguinarine, chelerythrine, and nitidine. Bioorgan. Med. Chem. 2006, 14, 5439-5445. [CrossRef]

6. Barreto, M.C.; Pinto, R.E.; Arrabaça, J.D.; Pavão, M.L. Inhibition of mouse liver respiration by Chelidonium majus isoquinoline alkaloids. Toxicol. Lett. 2003, 146, 37-47. [CrossRef]

7. Sedo, A.; Vlasicova, K.; Bartak, P.; Vespalec, R.; Vicar, J.; Simanek, V.; Ulrichova, J. Quaternary Benzo[c]phenanthridine Alkaloids as Inhibitors of Aminopeptidase N and Dipeptidyl Peptidase IV. Phytother. Res. 2002, 16, 84-87. [CrossRef]

8. Ulrichova, J.; Dvorak, Z.; Vicar, J.; Lata, J.; Smrzova, J.; Sedo, A.; Simanek, V. Cytotoxicity of natural compounds in hepatocyte cell culture models. The case of quaternary benzo[c]phenanthridine alkaloids. Toxicol. Lett. 2001, 125, 125-132. [CrossRef]

9. Zielinska, S.; Wójciak-Kosior, M.; Płachno, B.J.; Sowa, I.; Włodarczyk, M.; Matkowski, A. Quaternary alkaloids in Chelidonium majus in vitro cultures. Ind. Crop. Prod. 2018, 123, 17-24. [CrossRef]

10. Sowa, I.; Zielinska, S.; Sawicki, J.; Bogucka-Kocka, A.; Staniak, M.; Bartusiak-Szczesniak, E.; Podolska-Fajks, M.; Kocjan, R.; Wojciak-Kosior, M. Systematic evaluation of chromatographic parameters for isoquinoline alkaloids on XB-C18 core-shell column using different mobile phase compositions. J. Anal. Methods Chem. 2018, 3, 1-8. [CrossRef]

11. Borghini, A.; Pietra, D.; di Trapani, C.; Madau, P.; Lubinu, G.; Bianucci, A.M. Data mining as a predictive model for Chelidonium majus extracts production. Ind. Crop Prod. 2015, 64, 25-32. [CrossRef]

12. Gilca, M.; Gaman, L.; Panait, E.; Stoian, I.; Atanasiu, V. Chelidonium majus-An integrative review: Traditional knowledge versus modern findings. Complement. Med. Res. 2010, 17, 241-248. [CrossRef]

13. Sarközi, A.; Janicsak, G.; Kursinszki, L.; Kery, A. Alkaloid composition of Chelidonium majus L. studied by different chromatographic techniques. Chromatographia 2006, 63, S81-S86. [CrossRef]

14. Osbaldeston, T.A.; Wood, R.P.A. Dioscorides de Materia Medica, Being a Herbal with Many other Materials Written in Greek in the First Century of the Common Era; An Indexed Version in Modern English; Ibidis Press: Johannesburg, South Africa, 2000; pp. 352-355.

15. Jones, W.H.S. Pliny Natural History with an English Translation in Ten Volumes; Harvard University Press: London, UK, 1966.

16. Murashige, T.; Skoog, F. A revised medium for rapid growth and bioassays with tobacco tissue cultures. Physiol. Plant. 1962, 15, 473-497. [CrossRef]

17. Gamborg, O.L.; Miller, R.A.; Ojima, K. Nutrient requirements of suspension culture of soybean root cells. Exp. Cell Res. 1968, 50, 151-158. [CrossRef]

18. Kędzia, B.; Hołderna-Kędzia, E.; Goździcka-Józefiak, A.; Buchwald, W. The antimicrobial activity of Chelidonium majus L. Postępy Fitoterapii 2013, 4, 236-243.

19. Artini, M.; Papa, R.; Barbato, G.; Scoarughi, G.L.; Cellini, A.; Morazzoni, P.; Bombardelli, E.; Selan, L. Bacterial biofilm formation inhibitory activity revealed for plant derived natural compounds. Bioorg. Med. Chem. 2012, 20, 920-926. [CrossRef]

20. Mitscher, L.A.; Leu, R.P.; Bathala, M.S.; Wu, W.N.; Beal, J.L. Antimicrobial agents from higher plants. I. Introduction, rationale, and methodology. Lloydia 1972, 35, 157-166.

21. Mitscher, L.A.; Park, Y.H.; Clark, D.; Clark, G.W.; Hammesfahr, P.D.; Wu, W.N.; Beal, J.L. Antimicrobial agents from higher plants. An investigation of Hunnemannia fumariaefolia pseudoalcoholates of sanguinarine and chelerythrine. Lloydia 1978, 41, 145-149.

22. Kokoška, L.; Polesny, Z.; Rada, V.; Nepovim, A.; Vanek, T. Screening of some Siberian medicinal plants for antimicrobial activity. J. Ethnopharmacol. 2002, 82, 51-53. [CrossRef]

23. Ciric, A.; Vinterhalter, B.; Šavikin-Fodulovi'c, K.; Sokovic, M.; Vinterhalter, D. Chemical analysis and antimicrobial activity of methanol extracts of celandine (Chelidonium majus L.) plants growing in nature and cultured in vitro. Arch. Biol. Sci. 2008, 60,7-8. [CrossRef]

24. Wongbutdee, J. Physiological effects of berberine-Review article. Thai Pharm. Health Sci. J. 2009, 4, 78-83.

25. Imanshahidi, M.; Hosseinzadeh, H. Pharmacological and therapeutic effects of Berberis vulgaris and its active constituent, Berberine-Review article. Phytother. Res. 2008, 22, 999-1012. [CrossRef] 
26. Kedzia, B.; Hołderna-Kedzia, E. The effect of alkaloids and other groups of plant compounds on bacteria and fungi. Postęp. Fitoter. 2013, 1, 8-16.

27. Ma, W.G.; Fukushi, Y.; Tahava, S.; Osawa, T. Fungitoxic alkaloids from Hokkaido Papaveraceae. Fitoterapia 2000, 71, 527-534. [CrossRef]

28. Meng, F.; Zuo, G.; Hao, X.; Wang, G.; Xiao, H.; Zhang, J.; Xu, G. Antifungal activity of the benzo [c] phenanthridine alkaloids from Chelidonium majus Linn against resistant clinical yeast isolates. J. Ethnopharmacol. 2009, 125, 494-496. [CrossRef]

29. Young, I.M.; Crawford, J.W. Interactions and Self-Organization in the Soil-Microbe Complex. Science 2004, 304, 1634-1637. [CrossRef]

30. Djenane, Z.; Nateche, F.; Amziane, M.; Gomis-Cebolla, J.; El-Aichar, F.; Khorf, H.; Ferre, J. Assessment of the Antimicrobial Activity and the Entomocidal Potential of Bacillus thuringiensis Isolates from Algeria. Toxins 2017, 9, 139. [CrossRef]

31. Schirawski, J.; Perlin, H. Plant-Microbe Interaction 2017-The Good, the Bad and the Diverse. Int. J. Mol. Sci. 2018, 19, 1374. [CrossRef]

32. Wand, M.E.; Bock, L.J.; Bonney, L.C.; Sutton, J.M. Mechanisms of Increased Resistance to Chlorhexidine and Cross-Resistance to Colistin following Exposure of Klebsiella pneumoniae Clinical Isolates to Chlorhexidine. Antimicrob. Agents Chemother. 2017, 61, 01162-16. [CrossRef]

33. Kulp, M.; Bragina, O.; Kogerman, P.; Kaljurand, M. Capillary electrophoresis with LED-induced native fluorescence detection for determination of isoquinoline alkaloids and their cytotoxicity in extracts of Chelidonium majus L. J. Chromatogr. A 2011, 1218, 5298-5304. [CrossRef]

(C) 2019 by the authors. Licensee MDPI, Basel, Switzerland. This article is an open access article distributed under the terms and conditions of the Creative Commons Attribution (CC BY) license (http://creativecommons.org/licenses/by/4.0/). 